\title{
Mapeamento eletrônico e estudo estrutural deinibidores da Tirosina Quinase Abl-Bcr.
}

\author{
*Washington A. Pereira ${ }^{1}$ (PG), Érica C. M. Nascimento ${ }^{2}$ (PQ), João B. L. Martins ${ }^{1}$ (PQ). \\ was.a.pra@gmail.com \\ ${ }^{1}$ Universidade de Brasília, Laboratório de Química computacional, IQ, CP 4478, Brasília-DF, Brasil. \\ ${ }^{2}$ Departamento de Química Fí sica y Analítica, Universitat Jaume I, Castellón, Espanha.
}

\section{RESUMO}

A proteína tirosina quinase Bcr-Abl, é a responsável por um tipo específico de neoplasia conhecida como leucemia mieloide crônica (LMC), Este tipo de câncer é caracterizado pelo excesso da produção de glóbulos brancos no organismo. A LMC é uma doença terminal e a única forma de tratamento é o transplante de medula óssea. ${ }^{1,2}$ A forma de tratamento da LMC passou por várias modificações no decorrer das décadas, a partir dos anos 2000 o tratamento passou a ser feito com os inibidores da classe dos TINIBES, moléculas que inibem a proteína tirosina Abl-Bcr com o inteuito de aumentar a sobrevida dos pacientes. ${ }^{3}$ Os métodos de cálculos quânticos de estrutura eletrônica como DFT e os métodos semiempíricos, são amplamente empregados no estudo das propriedades eletrônicas e estruturais. Estes métodos são valiosas ferramentas no estudo de drug design na busca de novos inibidores. ${ }^{4}$

Palavras-chave: Tirosina Quinase, Inibidores, estrutura eletrônica, DFT.

O tratamento da LMC na fase crônica se dá pelo uso de moléculas que atuam como inibidores da tirosina quinase $(\mathrm{TKI})^{5}$. Esses inibidores se ligam ao sítio ativo da proteína bloqueando que seu substrato natural acesse o sítio catalítico, impedindo a fosforização da enzima. ${ }^{6}$

O imatinibe é um fármaco desenvolvido e produzido pela indústria farmacêutica Novartis, revolucionou o tratamento da LMC. É o fármaco de primeira linha, ou seja aquele com o qual se inicia o tratamento. Porém, devido as complicações diversas apresentadas pelos pacientes o uso do Imatinibe deve ser breve, sendo este fármaco substituído por outros Tinibes como o dasatinibe, nilotinibe e o ponatinibe. ${ }^{7}$

O Estudo das propriedades eletrônicas dos inibidores usando os método DFT/B3LYP e MP4 com a função de base $6-311+\mathrm{g}(\mathrm{d}, \mathrm{p})$ foram realizados. Estes cálculos foram realizados para descrever as características que levam estes ligantes a interagirem com a enzima tirosina quinase. ${ }^{7}$

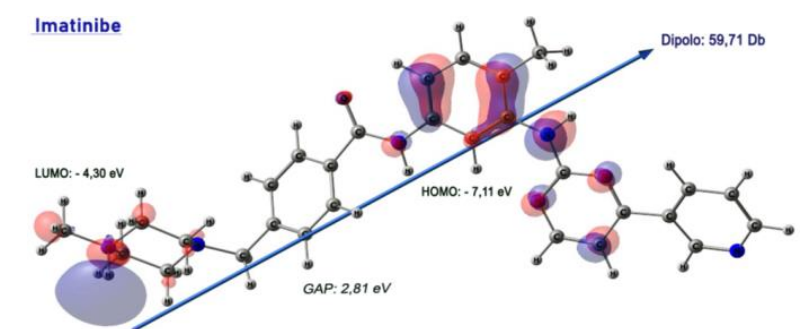

Figura 1. Orbitais de fronteira HOMO e LUMO e vetor de dipolo do imatinibe. Cálculos realizados com método DFT/B3LYP 6-311+(d,p).

\section{Referências}

[1] Carlos M. R. SantâAnna. Métodos de modelagem molecular para estudo e planejamento de compostos bioativos: Uma introdução. Revista Virtual de Química, 1(1):49-57, 2009. 
[2] Maria de Lourdes Lopes Ferrari Chauffaille. Leucemia mieloide crônica: tratamento baseado em evidências. Clínica Médica Ou Diagnóstico Tratamento, São Paulo, 14(2):62-65, 2009.

[3] Gabriel Heerdt and Nelson H. Morgon. Validação computacional de métodos compostos no estudo de propriedades moleculares. Química Nova, 34(5):868-873, 2011.

[4] Alphy Rose James, BS Unnikrishnan, R Priya, Manu M Joseph, TK Manojkumar, K Raveendran Pillai, R Shiji, GU Preethi, P Kusumakumary, and TT Sreelekha. Computational and mechanistic studies on the effect of galactoxyloglucan: Imatinib nanoconjugate in imatinib resistant k562 cells. Tumor Biology, 39(3):1010428317695946, 2017.

[5] Caio Abner V. G. Leite, José Victor G. Costa, Rodrigo B. Callado, João Nathanael L. Torres, and Roberto César P Lima. Receptores tirosina-quinase: implicações terapêuticas no câncer. Revista Brasileira de Oncologia Clínica, 8(29):140-142, 2012.

[6] Taira Maekawa, Eishi Ashihara, and Shinya Kimura. The bcr-abl tyrosine kinase inhibitor imatinib and promising new agentes against Philadelphia chromosome-positive leukemias. International journal of clinical oncology, 12 (5): 327-340, 2007.

[7] Ruriko Tanaka and Shinya Kimura. Abl tyrosine kinase inhibitors for overriding bcrabl/t315i: from the second to third generation. Expert review of anticancer therapy, 8(9):1387-1398, 2008. 